\title{
Low-Temperature Annealing Induced Amorphization in Nanocrystalline NiW Alloy Films
}

\author{
Z. Q. Chen, ${ }^{1}$ F. Wang, ${ }^{2}$ P. Huang, ${ }^{1}$ T. J. Lu, ${ }^{2}$ and K. W. Xu ${ }^{1}$ \\ ${ }^{1}$ State-Key Laboratory for Mechanical Behavior of Material, Xi'an Jiaotong University, Xian 710049, China \\ ${ }^{2}$ State-Key Laboratory for Strength and Vibration of Mechanical Structures, School of Aerospace, Xian Jiaotong University, \\ Xian 710049, China
}

Correspondence should be addressed to F. Wang; wangfei@mail.xjtu.edu.cn and P. Huang; huangping@mail.xjtu.edu.cn

Received 23 May 2013; Accepted 20 July 2013

Academic Editor: Fathallah Karimzadeh

Copyright (C) 2013 Z. Q. Chen et al. This is an open access article distributed under the Creative Commons Attribution License, which permits unrestricted use, distribution, and reproduction in any medium, provided the original work is properly cited.

\begin{abstract}
Annealing induced amorphization in sputtered glass-forming thin films was generally observed in the supercooled liquid region. Based on X-ray diffraction and transmission electron microscope (TEM) analysis, however, here, we demonstrate that nearly full amorphization could occur in nanocrystalline (NC) sputtered NiW alloy films annealed at relatively low temperature. Whilst the supersaturation of $\mathrm{W}$ content caused by the formation of $\mathrm{Ni}_{4} \mathrm{~W}$ phase played a crucial role in the amorphization process of $\mathrm{NiW}$ alloy films annealed at $473 \mathrm{~K}$ for $30 \mathrm{~min}$, nearly full amorphization occurred upon further annealing of the film for $60 \mathrm{~min}$. The redistribution of free volume from amorphous regions into crystalline regions was proposed as the possible mechanism underlying the nearly full amorphization observed in NiW alloys.
\end{abstract}

Crystallization often occurs upon annealing amorphous metals because crystalline phases are more thermodynamically stable than amorphous phases [1-3]. In the opposite way, it has also been reported that amorphization could take place while sputtered crystalline metal film was annealed in the temperature range between the glass transition temperature and the crystallization temperature, that is, the supercooled liquid region [4-7]. It was proposed that, while annealed in certain temperature range, the high thermal and interfacial energies between nanocrystalline (NC) and glassy matrices could lead to amorphization. Despite that, upon annealing, there may exist an alternative way to derive amorphous phase from crystalline phase.

It has been well documented that NC metals, in particular pure elemental NC metals, are thermally unstable due to the high energy associated with the large volume fraction of grain boundaries (GBs). They usually exhibit tremendous grain growth upon annealing [8-13], even at modest temperature $[14,15]$. On the other hand, alloying has been found to slow down the grain coarsening process in NC metals because additional solutes segregated in the GBs can reduce the total GB energy [16-20]. That is, NC alloys may sustain higher temperature and longer time than pure elemental NC metals without noticeable grain growth. However, upon lowtemperature annealing, $\mathrm{NC}$ alloys may undergo the process of GB relaxation [21, 22], in which defects like dislocations or voids annihilate in the GBs, and the GB structure becomes relatively ordered. As indicated by Detor and Schuh [18] and Rupert et al. [23], GB relaxation could occur in NC $\mathrm{NiW}$ alloy at temperatures ranging from 373 to $723 \mathrm{~K}$. In the present work, we report an amorphization process observed in sputtered NC NiW alloy thin film after the alloy is annealed at relatively low temperature $(473 \mathrm{~K})$. The possible mechanism of this distinctive phenomenon is proposed and discussed.

$\mathrm{Ni}(99.99 \%)$ and W (99.95\%) targets were used to deposit NiW alloy films on Si (100) substrates by using a D.C. magnetron sputtering system. The chamber was evacuated to a base pressure of $\sim 5 \times 10^{-4} \mathrm{~Pa}$, and a working pressure of $\sim 3 \times 10^{-1} \mathrm{~Pa}$ was maintained by Ar flow. The total thickness of the alloy film was $\sim 1 \mu \mathrm{m}$, and the substrate was neither heated nor cooled during deposition. Upon deposition, the as-deposited NiW films were vacuum-sealed $\left(\sim 10^{-3} \mathrm{~Pa}\right)$ in the same depositing chamber and annealed at $473 \mathrm{~K}$ for 30 and 


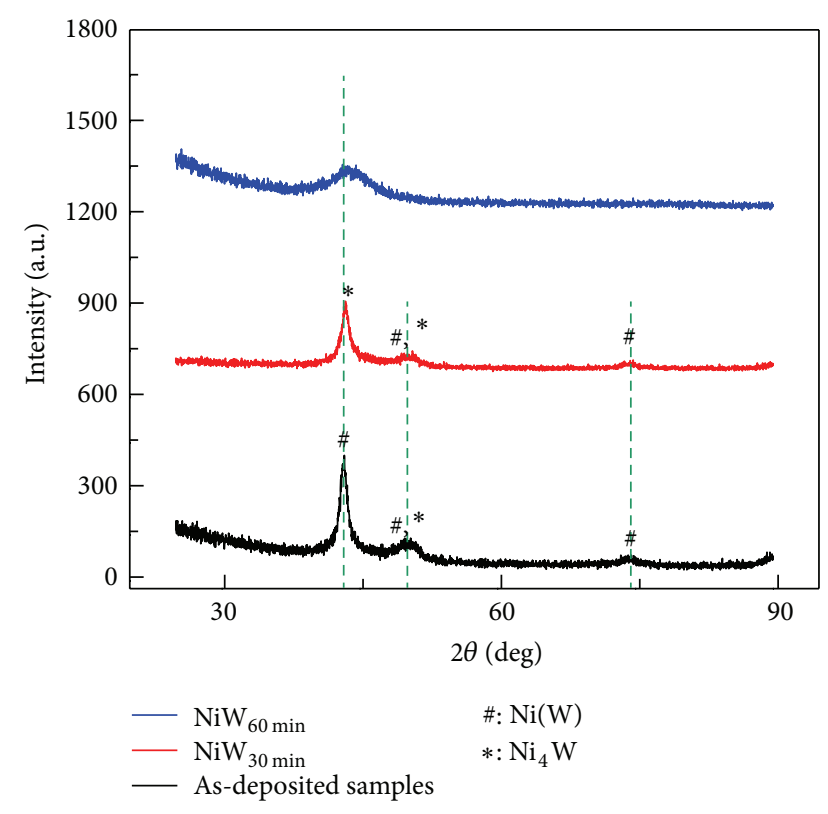

FIGURE 1: XRD profile of as-deposited NiW alloy, $\mathrm{NiW}_{30 \text { min }}$, and $\mathrm{NiW}_{60 \text { min }}$.

60 minutes (referred to as $\mathrm{NiW}_{30 \text { min }}$ and $\mathrm{NiW}_{60 \text { min }}$ hereafter, resp.). It should be noted that the annealing temperature of $473 \mathrm{~K}$ selected in the present study could avoid possible grain growth as reported previously $[18,23]$. X-ray diffraction (XRD) was performed via a XRD-7000 diffractometer (Shimadzu Corporation) at room temperature using $\mathrm{Cu} K \alpha$ radiation operated at $40 \mathrm{kV}$. Transmission electron microscope (TEM) and high resolution TEM (HRTEM) were conducted by JEM $2100 \mathrm{~F}$ microscope operated at $200 \mathrm{kV}$. In addition, energy dispersive X-ray spectroscopy (EDS) analysis was used to identify the elemental composition of NiW films.

XRD patterns of both the as-deposited and the annealed NiW films are shown in Figure 1. The as-deposited films exhibited a typical face-centered cubic (fcc) lattice structure, based on the identified (111) $\left(2 \theta=43.31^{\circ}\right),(200)(2 \theta=$ $\left.50.13^{\circ}\right)$, and $(220)\left(2 \theta=74.42^{\circ}\right)$ peaks of NiW. By annealing at $473 \mathrm{~K}$ for $30 \mathrm{~min}$, the lattice structure changed to bodycentered tetragonal (bct), which corresponds to $\mathrm{Ni}_{4} \mathrm{~W}$ as (211) $\left(2 \theta=43.52^{\circ}\right)$ and $(130)\left(2 \theta=50.34^{\circ}\right)$ peaks were observed. However, the peak at $2 \theta=74.42^{\circ}$ corresponding to $\mathrm{NiW}$ (220) still remained. More importantly, the intensities of those peaks observed in $\mathrm{NiW}_{30 \text { min }}$ were relatively lower and broader than those in the as-deposited NiW, indicating that amorphization may have already started. For $\mathrm{NiW}_{60 \text { min }}$, however, only a single broad diffraction peak was observed without detection of any diffraction peaks that referred to the crystalline phase, indicating that a fully amorphous structure was formed in the $\mathrm{NiW}_{60 \text { min }}$ film.

The cross-sectional bright field and dark field TEM micrographs of both as-deposited and annealed NiW films are presented in Figure 2. Specifically, the TEM images and the associated diffraction ring pattern shown in Figures 2(a) and 2(d) clearly indicated the typical columnar nanocrystalline structure of as-deposited NiW films. The grain size along the crystal growth direction was about dozens of nanometers or even more than a hundred nanometers. In plane-view, however, the grain size was estimated to be only $\sim 10 \mathrm{~nm}$. After annealing for $30 \mathrm{~min}$, the microstructure of $\mathrm{NiW}_{30 \text { min }}$ exhibited two-phase nanoscale composition of a columnar nanocrystalline matrix containing dispersed areas of amorphous structure, as shown in Figures 2(b) and 2(e). When the annealing time was extended to $60 \mathrm{~min}$, almost all of the microstructure had transformed into amorphous except a few crystalline areas near the free surface, as shown in Figures 2(c) and 2(f). The nearly full amorphization was confirmed by the inserted SAD pattern in Figure 2(c), consisting of diffuse halo and a few spots. The HRTEM images corresponding to the dark circles in Figures 2(a) to 2(c) were presented in Figures 2(g) to 2(i). For as-deposited NiW shown in Figure 2(g), only periodic lattice structures with a few stacking faults located in the middle of the columnar grain were observed. After annealing for $30 \mathrm{~min}$, local amorphization occurred as Figure 2(h) demonstrated that amorphous phase surrounded by crystalline structures appeared. Specifically, region "A" exhibited amorphous structure, whilst region " $\mathrm{B}$ " still maintained lattice structure. Eventually, as shown in Figure 2(i), nearly full amorphization was observed where only one crystalline grain of diameter $\sim 7 \mathrm{~nm}$ appeared. In addition, according to the EDS results (not shown here for brevity), for both as-deposited and annealed films, the compositions of $\mathrm{Ni}$ and $\mathrm{W}$ were about $77 \%$ and $23 \%$ (atom\%), respectively.

In general, there were two prerequisites for annealing induced amorphization in sputtering thin films: (1) high glass-forming alloy such as $\mathrm{ZrCuAlNi}$ [4], FeTiCoNiBNb [6], and $\mathrm{ZrCuAlTi}$ [7] should be used for deposition; (2) the asdeposited alloy should be annealed within the supercooled liquid region $[4,6,7]$. Under these circumstances, by observing annealing induced amorphization via in situ and ex situ TEM in sputtered glass-forming films, Chu et al. $[4,6,7]$ suggested that three effects may affect the amorphization process significantly: interfacial energy between nanocrystalline and amorphous matrices, low viscosity of amorphous matrix, and unstable sputtered crystalline phases. However, despite these prerequisites, nearly full amorphization occurred in the present NiW alloy thin films. For NiW having lower glass-forming ability than those alloys listed above, it has been reported that its crystallization temperature $\left(T_{x}\right)$ was more than $873 \mathrm{~K}$ [24] and its element-compositional state was similar to the present NiW alloy films. For amorphous materials [4-7], as the supercooled liquid region lies generally in a range of tens of Kelvin, the glass transition temperature $\left(T_{g}\right)$ of NiW thin films should be larger than $\sim 800 \mathrm{~K}$, much higher than the annealing temperature of NiW alloy films ( $473 \mathrm{~K}$ in the present study). Therefore, the physical mechanisms underlying low-temperature annealing induced amorphization observed in the present NiW alloy films may be quite different from previously proposed mechanisms for annealing induced amorphization [5].

It should be noted that amorphization could also be induced by either hydrogen [25] or oxidation [26]. Hydrogeninduced amorphization, occurring usually under high pressure (up to 50 atmospheres) and elevated temperature [25], could be excluded because the present NiW films were 


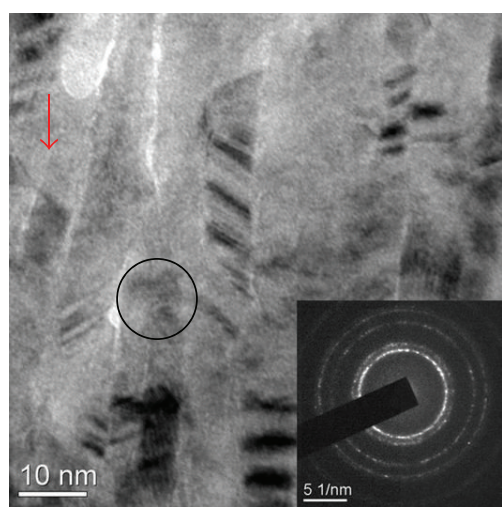

(a)

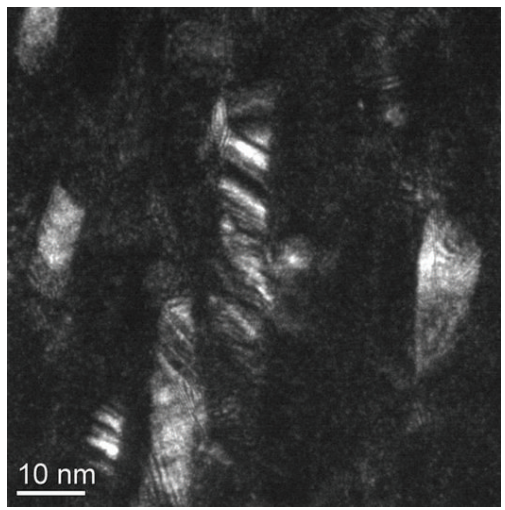

(d)

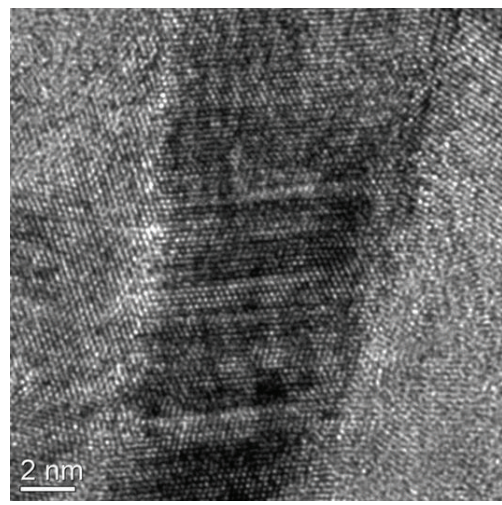

(g)

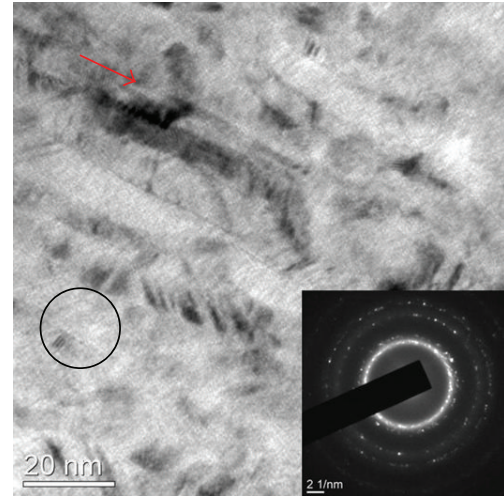

(b)

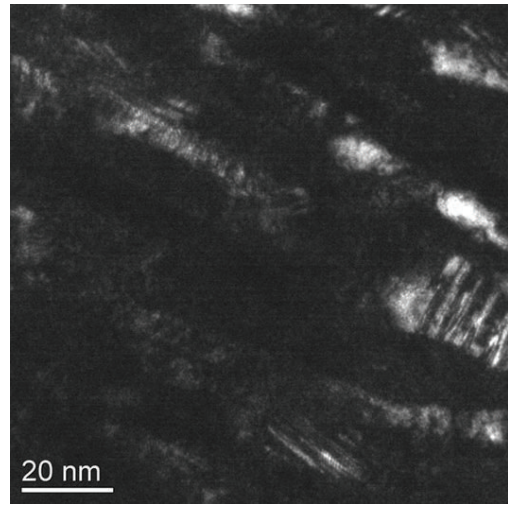

(e)

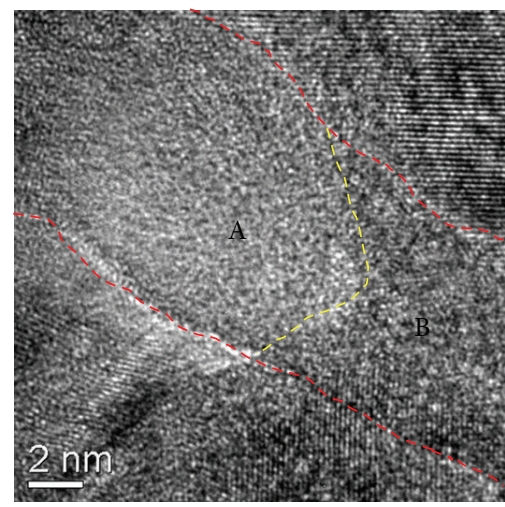

(h)

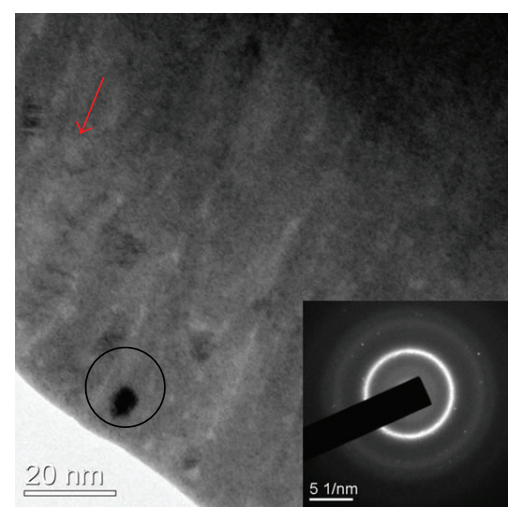

(c)

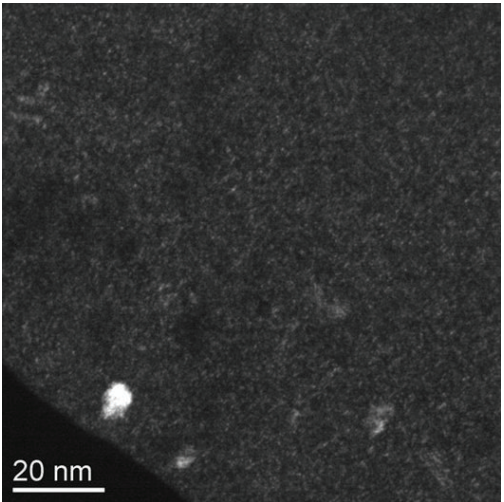

(f)

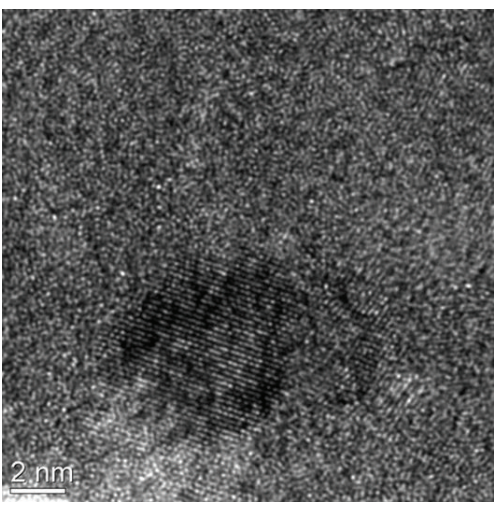

(i)

Figure 2: Cross-sectional bright field TEM micrographs of (a) as-deposited NiW alloy, (b) $\mathrm{NiW}_{30 \mathrm{~min}}$, and (c) $\mathrm{NiW}_{60 \mathrm{~min}}$. The red arrows shown in (a) to (c) denote crystal growth direction in the films. (d), (e), and (f) are dark field TEM micrographs corresponding to (a), (b), and (c), respectively. HRTEM images of the region indexed by a circle in (a), (b), and (c) are represented separately in (g), (h), and (i).

deposited under hydrogen-deficient and sufficiently low pressure circumstances. Whilst oxidation is known to promote amorphization in numerous binary $\mathrm{Al}-$ and $\mathrm{Zr}$-based alloys [26], its effect should also be ruled out here since neither oxidized phase nor oxygen layer was detected both inside the alloy film and on its free surface.

Other than the mechanisms previously proposed, we believe the supersaturation of $\mathrm{W}$ atoms in $\mathrm{Ni}$ matrix may play a crucial role in the amorphization process under lowtemperature annealing. Given that the solubility limit of W in NiW alloy is only $~ 12$ at.\% [27], the present NiW alloy with $\mathrm{W}$ content of $\sim 23$ at.\% should be in nonequilibrium state. Moreover, it has been indicated that amorphous phase would emerge when the content of $\mathrm{W}$ was sufficiently large, for example, 24 to 30 at.\% [28] and 28 at.\% [29] previously observed for NiW alloys, which were close to the $\mathrm{W}$ content ( 23 at.\%) of the present NiW alloy.

As shown in Figure 1, $\mathrm{Ni}_{4} \mathrm{~W}$ with $\mathrm{W}$ content of 20 at.\% was formed after $30 \mathrm{~min}$ annealing. The appearance of the $\mathrm{Ni}$-rich phase, that is, $\mathrm{Ni}_{4} \mathrm{~W}$ (consisting of only 20 at. $\% \mathrm{~W}$ ), 
could increase the $\mathrm{W}$ content in the rest of the regions to beyond the solubility limits, that is, 24 to 30 at.\% [28] and $\sim 28$ at.\% [29] for NiW alloys. Once the solubility limit was reached, amorphous phase would appear as observed in Figures 2(b), 2(e), and 2(h). It should be noted, however, that W could accumulate in GBs by segregation, which might reduce the total energy in NiW alloys [18]. Despite that, it has been revealed that solute segregation to GBs in NC $\mathrm{NiW}$ alloys was most pronounced in the dilute limit, and the segregation tendency decreased with further alloying addition $[20,28,30]$. Indeed, in the present as-deposited $\mathrm{NiW}$ alloy thin films (23 at.\% W), Ni atoms and $\mathrm{W}$ atoms distribute uniformly; only $\sim 2$ at.\% segregation was detected in GBs by EDS analysis, indicated by Figure 3. Therefore, the low segregation tendency in the present $\mathrm{NiW}$ alloy resulted in negligible effect of GB segregation on the $\mathrm{W}$ content, and, upon annealing for $30 \mathrm{~min}$, the majority of the excess $\mathrm{W}$ atoms derived after forming $\mathrm{Ni}_{4} \mathrm{~W}$ were nearly homogeneously distributed in both inter- and intragranular regions. Under these circumstances, the content of $\mathrm{W}$ in certain regions might exceed the aforementioned amorphous forming limits, causing phase transformation from nanocrystalline to amorphous structure as shown in Figures 2(b), 2(e), and $2(\mathrm{~h})$.

The volume fraction of supersaturated regions upon annealing may be estimated semiquantitatively. More than twenty cross-sectional TEM bright-field and dark-field images were used to calculate the volume fraction of grain boundaries, and the representative TEM images were shown in Figure 2. Here, we assume that the columnar grains in the as-deposited films were standard circular columns of length $50 \mathrm{~nm}$ in the cross-sectional direction and diameter $10 \mathrm{~nm}$ in the plane-view direction. The volume fraction of the GBs $\left(V_{\mathrm{GB}}\right)$ may hence be estimated as $\sim 20.6 \%$ (width of GB assumed to be $1 \mathrm{~nm}$ ). The total content of $\mathrm{W}$ in the NiW alloy, $f_{\text {total }}$, may be calculated as

$$
\begin{aligned}
f_{\text {total }} & =f_{\mathrm{GB}} V_{\mathrm{GB}}+f_{m} V_{m}+f_{s} V_{s} \\
& =f_{\mathrm{GB}} V_{\mathrm{GB}}+f_{m}\left(1-V_{\mathrm{GB}}-V_{s}\right)+f_{s} V_{s},
\end{aligned}
$$

where $f_{\mathrm{GB}}, f_{m}$, and $f_{s}$ denoted separately the $\mathrm{W}$ content in GBs, matrix, and supersaturated regions, and $V_{\mathrm{GB}}, V_{m}$, and $V_{s}$ were the corresponding volume fractions. With $f_{\text {total }}=0.23$, $f_{m}=0.2$, and $V_{\mathrm{GB}}=0.206$, Figure 4 shows the dependence of $V_{s}$ upon $f_{s}$ when $f_{\mathrm{GB}}$ was varied in the range from 0.22 to 0.28 . The upper and lower limits for amorphous forming in NiW alloys ( 24 and 30 at.\% [28]) were indicated by dashed lines in Figure 4. Accordingly, for the present NiW alloy, the volume fraction of supersaturated regions (corresponding to those regions changed to amorphous phase after $30 \mathrm{~min}$ annealing treatment) should vary in the range from $\sim 27 \%$ to $65 \%$, as the degree of segregation in GBs was about 0.22 . The estimated volume fraction of the supersaturated regions was consistent with the amorphous regions observed experimentally, as shown in Figures 2(b), 2(e), and 2(f).

Upon annealing at $473 \mathrm{~K}$ for $60 \mathrm{~min}$, nearly full amorphization occurred as shown in Figures 2(c), 2(f), and 2(i). The dominant mechanism(s) for the unusual amorphization process, which broke down nearly all the crystalline structure

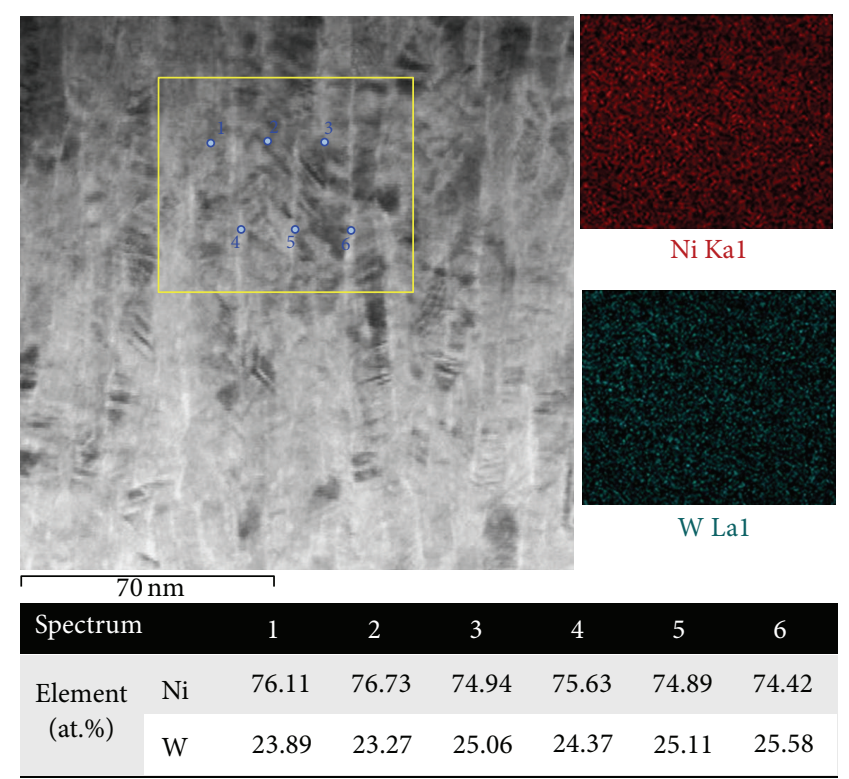

FIGURE 3: EDS results of the as-deposited NiW alloy film. Scanning of the region indicated by the yellow rectangle shows that $\mathrm{Ni}$ atoms and $\mathrm{W}$ atoms distribute uniformly. Scanning of the six randomly selected spots, point 1,2, and 3 located at intragranular region and point 4, 5, and 6 located at GBs region, indicates that only $\sim 2$ at. $\%$ segregation was detected in GBs.

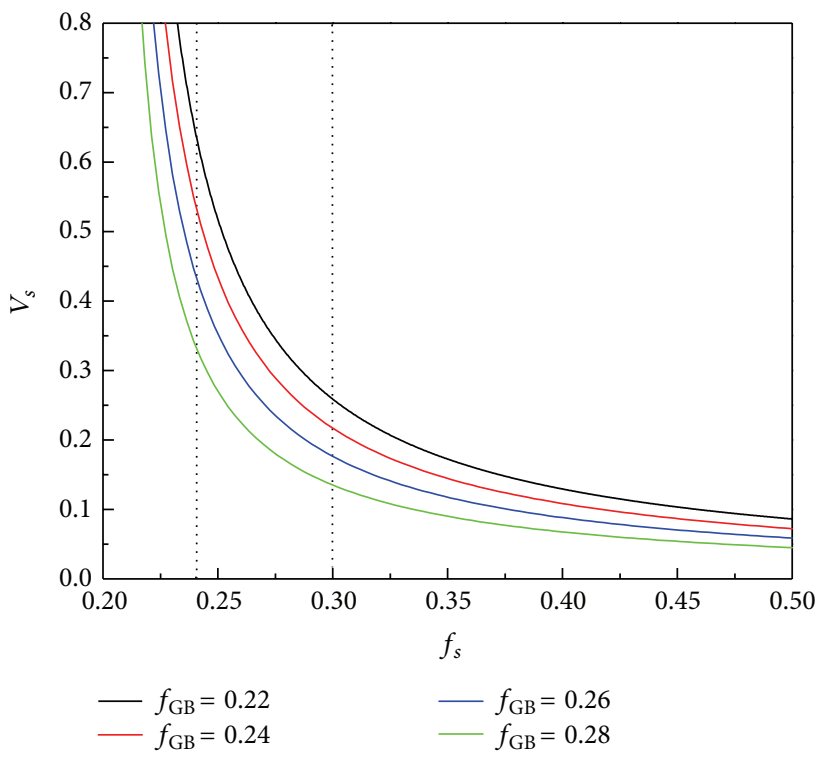

FIGURE 4: Predicted dependence of $V_{s}$ upon $f_{s}$ for $f_{\mathrm{GB}}$ ranging from 0.22 to 0.28 , with the two dashed lines representing the range of solubility limit (24 at.\% to 30 at.\%) for NiW alloys as reported in [28].

in the present NiW alloy after further annealing, remains unclear. This may be associated with a rearrangement of atoms between amorphous and crystalline regimes, analogous to the free volume expanding process previously proposed for nanoglass [31, 32]. For nanoglass containing a large amount of glass/glass interfaces, the interfaces may be delocalized upon annealing, causing the free volumes initially 


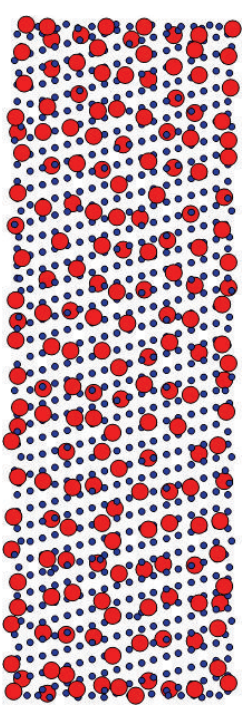

(a)

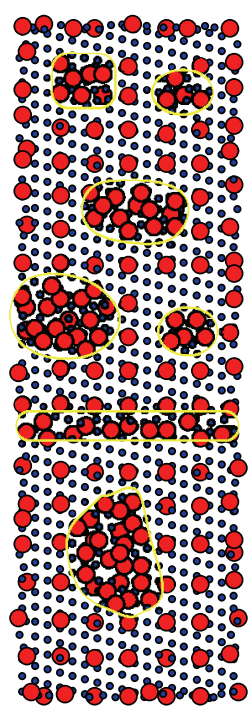

(b)

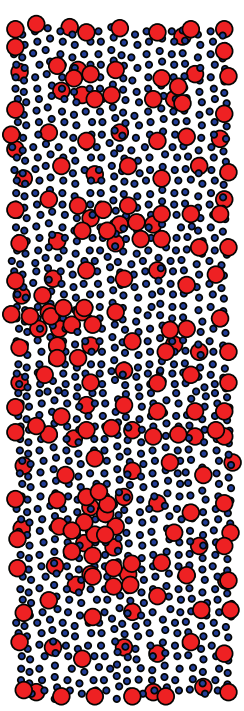

(c)

Figure 5: Schematic of microstructure evolution from (a) as-deposited NiW alloy, to (b) after 30 min annealing, and eventually to (c) after further 60 min annealing: (a) represents a columnar grain, with W atoms (red) distributed in Ni (blue) matrix; (b) illustrates the appearance of bct $\mathrm{Ni}_{4} \mathrm{~W}$ structure and the regions already changed to amorphous structure; and (c) illustrates the collapsing of nearly the entire crystalline structure after further annealing.

located in the glass/glass interfaces to expand uniformly over the entire nanoglass [33-35]. Then, the scenario as illustrated in Figure 5 may take place in the $30 \mathrm{~min}$ annealed NiW alloy after further annealing for $60 \mathrm{~min}$, which may cause nearly all the crystalline structure to break down. Figure 5(a) depicted schematically a columnar grain in the as-deposited NiW alloy, with $\mathrm{W}$ and $\mathrm{Ni}$ atoms indicated by red and blue filled circles, respectively. After annealing for $30 \mathrm{~min}$, as previously discussed, Figure 5(b) indicated that amorphization due to supersaturation of $\mathrm{W}$ atoms in Ni matrix occurred in some regions. Upon further annealing for $60 \mathrm{~min}$, as shown in Figure 5(c), the free volume in amorphous regions would be reduced while structural relaxation occurred. Then, the redundant free volume could only enter the surrounding crystalline regions, that is, the derived $\mathrm{Ni}_{4} \mathrm{~W}$ lattice structure after $30 \mathrm{~min}$ annealing, which was in metastable supersaturate state according to its equilibrium phase diagram. Eventually, a large proportion of the redundant free volume might be expanded uniformly over the $\mathrm{Ni}_{4} \mathrm{~W}$ lattice structure, and the metastable crystalline regions changed into the relatively stable amorphous phase, the latter having a relatively lower free energy than the crystalline phase.

In summary, nearly full amorphization in sputtered nanocrystalline NiW alloy films induced by low-temperature annealing was observed experimentally. It was proposed that the supersaturation of $\mathrm{W}$ atoms in Ni matrix played a key role in the amorphization process when the annealing lasted for $30 \mathrm{~min}$. Upon annealing for a further $60 \mathrm{~min}$, it was proposed that the redistribution of free volume from amorphous regions into crystalline regions may eventually break down the residual crystalline structure, causing the nearly full amorphization. Low-temperature annealing induced amorphization technique should be a simple and convenient method for preparation of amorphous metals. It can be used to produce some amorphous alloys with unique composition, which can be hardly produced by the traditional method.

\section{Acknowledgments}

This work was financially supported by the National Basic Research Program of China (2010CB631002, 2011CB610306), the National Natural Science Foundation of China (51171141, 51271141), the Program for New Century Excellent Talents in University (NCET-11-0431), the Research Fund for the Doctoral Program of Higher Education of China (20120201110001), and the Fundamental Research Funds for the Central Universities.

\section{References}

[1] A. Inoue, "Stabilization of metallic supercooled liquid and bulk amorphous alloys," Acta Materialia, vol. 48, no. 1, pp. 279-306, 2000.

[2] E. Pekarskaya, J. F. Löffler, and W. L. Johnson, "Microstructural studies of crystallization of a Zr-based bulk metallic glass," Acta Materialia, vol. 51, no. 14, pp. 4045-4057, 2003.

[3] I. Martin, T. Ohkubo, M. Ohnuma, B. Deconihout, and K. Hono, "Nanocrystallization of $\mathrm{Zr}_{41.2} \mathrm{Ti}_{13.8} \mathrm{Cu}_{12.5} \mathrm{Ni}_{10.0} \mathrm{Be}_{22.5}$ metallic glass," Acta Materialia, vol. 52, no. 15, pp. 4427-4435, 2004.

[4] J. P. Chu, C. T. Liu, T. Mahalingam et al., "Annealing-induced full amorphization in a multicomponent metallic film," Physical Review B, vol. 69, no. 11, Article ID 113410, 4 pages, 2004.

[5] J. P. Chu, "Annealing-induced amorphization in a glass-forming thin film," JOM, vol. 61, no. 1, pp. 72-75, 2009. 
[6] J. P. Chu, C.-T. Lo, Y.-K. Fang, and B.-S. Han, "On annealinginduced amorphization and anisotropy in a ferromagnetic Febased film: a magnetic and property study," Applied Physics Letters, vol. 88, no. 1, Article ID 012510, 2006.

[7] J. P. Chu, C.-Y. Wang, L. J. Chen, and Q. Chen, "Annealinginduced amorphization in a sputtered glass-forming film: insitu transmission electron microscopy observation," Surface and Coatings Technology, vol. 205, no. 8-9, pp. 2914-2918, 2011.

[8] S. X. McFadden, R. S. Mishra, R. Z. Vallev, A. P. Zhilyaev, and A. K. Mukherjee, "Low-temperature superplasticity in nanostructured nickel and metal alloys," Nature, vol. 398, no. 6729, pp. 684-686, 1999.

[9] G. K. Rane, U. Welzel, and E. J. Mittemeijer, "Grain growth studies on nanocrystalline Ni powder," Acta Materialia, vol. 60, no. 20, pp. 7011-7023, 2012.

[10] G. Sharma, J. Varshney, A. C. Bidaye, and J. K. Chakravartty, "Grain growth characteristics and its effect on deformation behavior in nanocrystalline Ni," Materials Science and Engineering A, vol. 539, pp. 324-329, 2012.

[11] J. Kacher, I. M. Robertson, M. Nowell, J. Knapp, and K. Hattar, "Study of rapid grain boundary migration in a nanocrystalline Ni thin film," Materials Science and Engineering A, vol. 528, no. 3, pp. 1628-1635, 2011.

[12] A. J. Haslam, D. Moldovan, S. R. Phillpot, D. Wolf, and H. Gleiter, "Combined atomistic and mesoscale simulation of grain growth in nanocrystalline thin films," Computational Materials Science, vol. 23, no. 1-4, pp. 15-32, 2002.

[13] G. D. Hibbard, K. T. Aust, and U. Erb, "On interfacial velocities during abnormal grain growth at ultra-high driving forces," Journal of Materials Science, vol. 43, no. 19, pp. 6441-6452, 2008.

[14] C. Detavernier, D. Deduytsche, R. L. Van Meirhaeghe, J. De Baerdemaeker, and C. Dauwe, "Room-temperature grain growth in sputter-deposited Cu films," Applied Physics Letters, vol. 82, no. 12, pp. 1863-1865, 2003.

[15] M. Ames, J. Markmann, R. Karos, A. Michels, A. Tschöpe, and R. Birringer, "Unraveling the nature of room temperature grain growth in nanocrystalline materials," Acta Materialia, vol. 56, no. 16, pp. 4255-4266, 2008.

[16] J. R. Weertman, "Retaining the nano in nanocrystalline alloys," Science, vol. 337, no. 6097, pp. 921-922, 2012.

[17] T. Chookajorn, H. A. Murdoch, and C. A. Schuh, "Design of stable nanocrystalline alloys," vol. Science337, no. 6097, pp. 951954, 2012.

[18] A. J. Detor and C. A. Schuh, "Microstructural evolution during the heat treatment of nanocrystalline alloys," Journal of Materials Research, vol. 22, no. 11, pp. 3233-3248, 2007.

[19] A. J. Detor and C. A. Schuh, "Tailoring and patterning the grain size of nanocrystalline alloys," Acta Materialia, vol. 55, no. 1, pp. 371-379, 2007.

[20] A. J. Detor, M. K. Miller, and C. A. Schuh, "Solute distribution in nanocrystalline Ni-W alloys examined through atom probe tomography," Philosophical Magazine, vol. 86, no. 28, pp. 44594475, 2006.

[21] H. Li, F. Jiang, S. Ni et al., "Mechanical behaviors of as-deposited and annealed nanostructured Ni-Fe alloys," Scripta Materialia, vol. 65, no. 1, pp. 1-4, 2011.

[22] F. Ebrahimi and H. Li, "The effect of annealing on deformation and fracture of a nanocrystalline fcc metal," Journal of Materials Science, vol. 42, no. 5, pp. 1444-1454, 2007.

[23] T. J. Rupert, J. R. Trelewicz, and C. A. Schuh, "Grain boundary relaxation strengthening of nanocrystalline Ni-W alloys," Journal of Materials Research, vol. 27, no. 9, pp. 1285-1294, 2012.
[24] P. Schloßmacher and T. Yamasaki, "Structural analysis of electroplated amorphous-nanocrystalline Ni-W," Mikrochimica Acta, vol. 132, no. 2-4, pp. 309-313, 2000.

[25] X. L. Yeh, K. Samwer, and W. L. Johnson, "Formation of an amorphous metallic hydride by reaction of hydrogen with crystalline intermetallic compounds-a new method of synthesizing metallic glasses," Applied Physics Letters, vol. 42, no. 3, pp. 242-243, 1983.

[26] H. Sieber, G. Wilde, and J. H. Perepezko, “Thermally activated amorphous phase formation in cold-rolled multilayers of Al$\mathrm{Ni}, \mathrm{Al}-\mathrm{Ta}, \mathrm{Al}-\mathrm{Fe}$ and $\mathrm{Zr}-\mathrm{Cu}$," Journal of Non-Crystalline Solids, vol. 250-252, pp. 611-615, 1999.

[27] A. Gabriel, H. L. Lukas, C. H. Allibert, and I. Ansara, "Experimental and calculated phase diagrams of the Ni-W, Co-W and Co-Ni-W system," Zeitschrift für Metallkunde, vol. 76, no. 9, pp. 589-595, 1985.

[28] T. J. Rupert, J. C. Trenkle, and C. A. Schuh, "Enhanced solid solution effects on the strength of nanocrystalline alloys," Acta Materialia, vol. 59, no. 4, pp. 1619-1631, 2011.

[29] A. O. Aning, Z. Wang, and T. H. Courtney, "Tungsten solution kinetics and amorphization of nickel in mechanically alloyed NiW alloys," Acta Metallurgica Et Materialia, vol. 41, no. 1, pp. 165-174, 1993.

[30] A. J. Detor and C. A. Schuh, "Grain boundary segregation, chemical ordering and stability of nanocrystalline alloys: atomistic computer simulations in the Ni-W system," Acta Materialia, vol. 55, no. 12, pp. 4221-4232, 2007.

[31] H. Gleiter, "Nanocrystalline solids," Journal of Applied Crystallography, vol. 24, no. 2, pp. 79-90, 1991.

[32] J. Jing, A. Krämer, R. Birringer, H. Gleiter, and U. Gonser, "Modified atomic structure in a PdFeSi nanoglass. A Mössbauer study," Journal of Non-Crystalline Solids, vol. 113, no. 2-3, pp. 167170, 1989.

[33] H. Gleiter, "Our thoughts are ours, their ends none of our own: are there ways to synthesize materials beyond the limitations of today?" Acta Materialia, vol. 56, no. 19, pp. 5875-5893, 2008.

[34] D. Şopu, K. Albe, Y. Ritter, and H. Gleiter, "From nanoglasses to bulk massive glasses," Applied Physics Letters, vol. 94, no. 19, Article ID 191911, 2009.

[35] T.-H. Yang, R.-T. Huang, C.-A. Wu et al., "Effect of annealing on atomic ordering of amorphous ZrTaTiNbSi alloy," Applied Physics Letters, vol. 95, no. 24, Article ID 241905, 2009. 

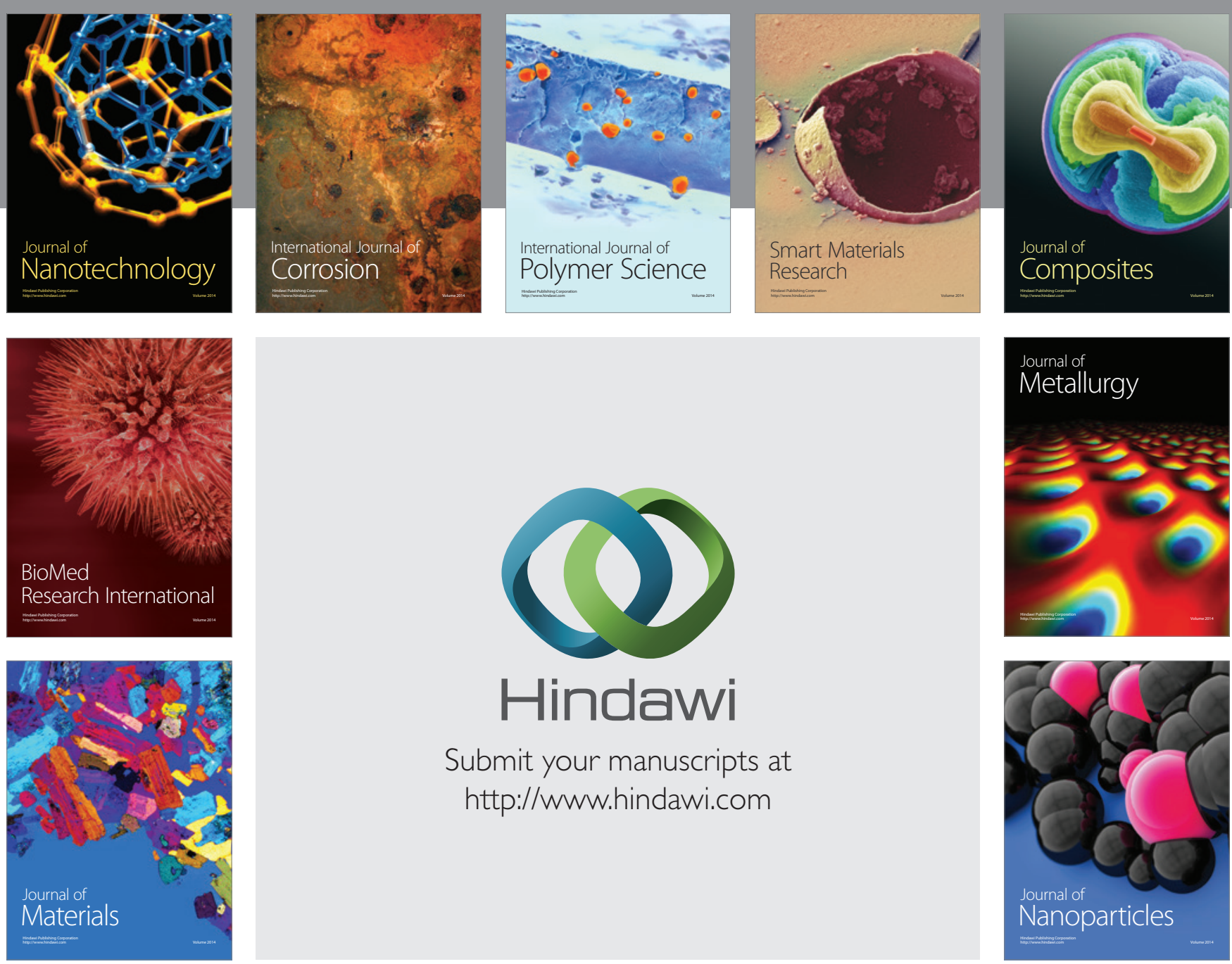

Submit your manuscripts at http://www.hindawi.com
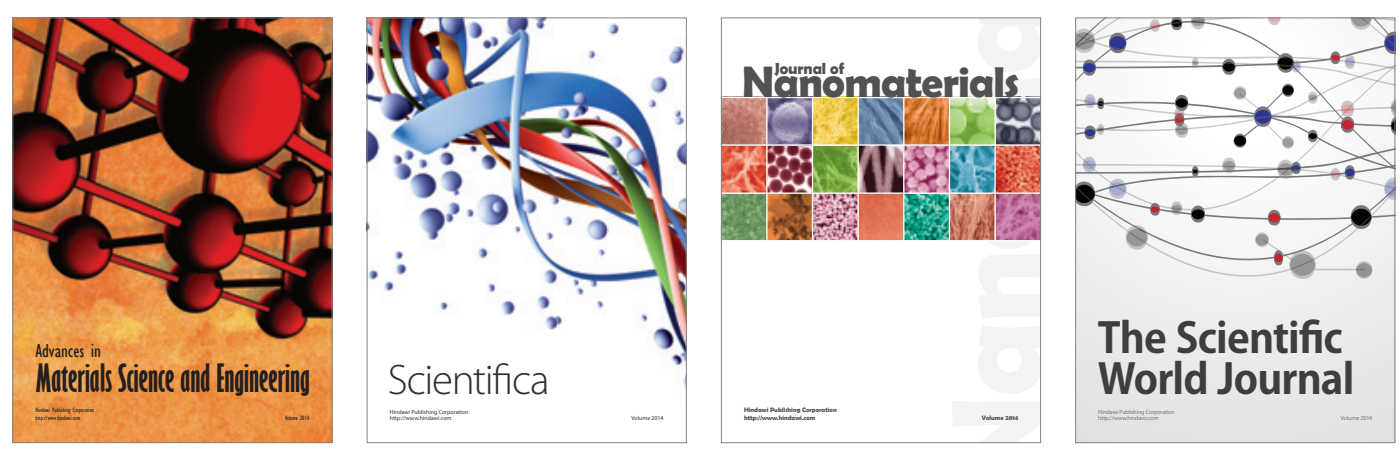

\section{The Scientific World Journal}
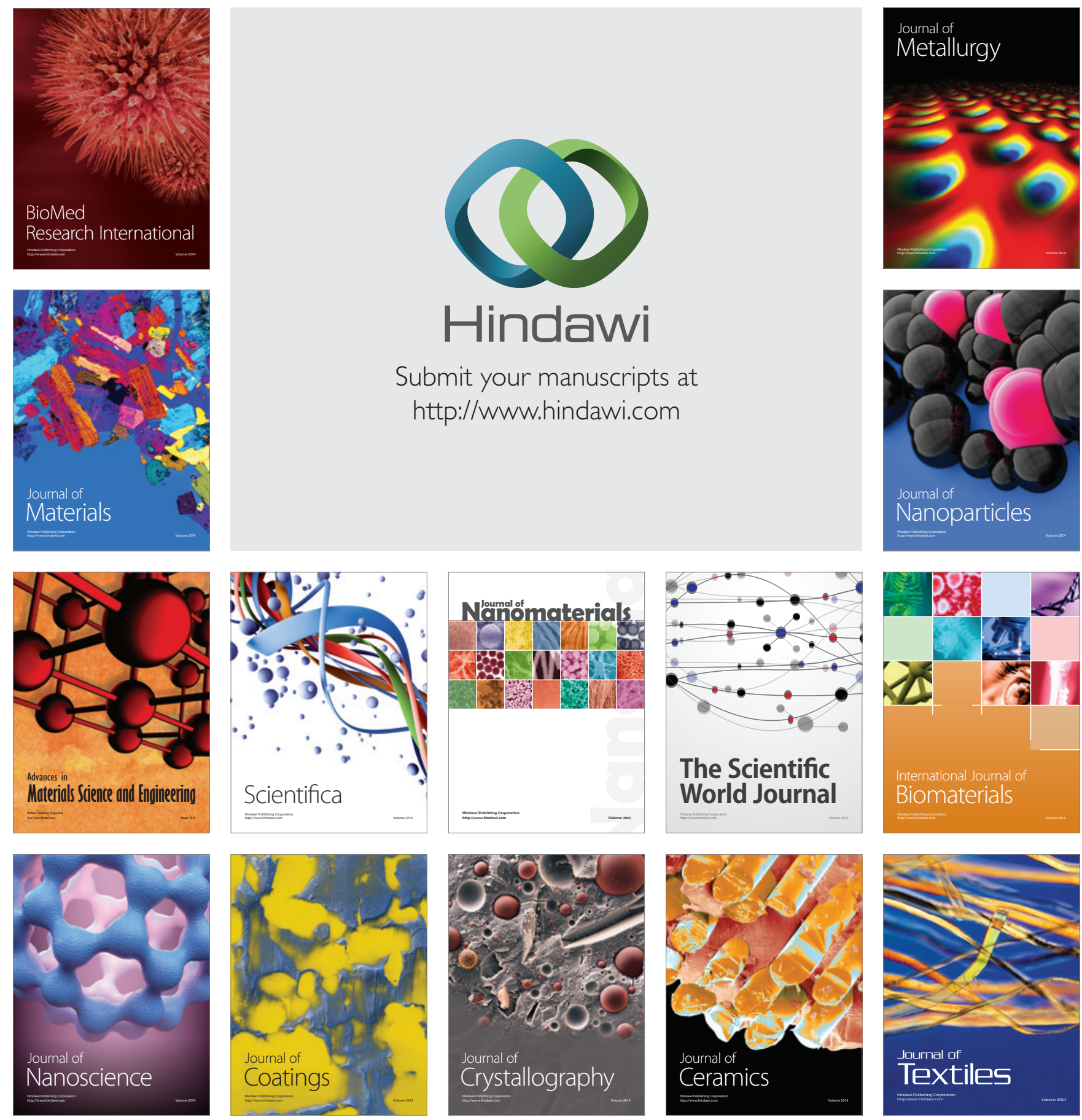